\title{
Serotonin Selectively Attenuates Glutamate-Evoked Activation of Noradrenergic Locus Coeruleus Neurons
}

\author{
Gary Aston-Jones, ${ }^{1}$ Hideo Akaoka, ${ }^{1}$ Paul Charléty, ${ }^{2}$ and Guy Chouvet ${ }^{2}$ \\ ${ }^{2}$ INSERM Unité 171 and CNRS URA1195, Centre Hospitalier Lyon Sud, 69310 Pierre Bénite, France, and 'Division of \\ Behavioral Neurobiology, Department of Mental Health Sciences, Hahnemann University Medical School, Philadelphia, \\ Pennsylvania 19102
}

\begin{abstract}
The effect of 5-HT on activity of noradrenergic locus coeruleus (LC) neurons was studied using microiontophoretic and micropressure drug application in anesthetized rats. 5-HT had no consistent effect on LC spontaneous discharge, eliciting a modest decrease overall. However, $5-\mathrm{HT}$ reliably attenuated responses of $L C$ neurons to excitatory amino acids (EAAs), one of the major classes of transmitters in afferents to these neurons. This effect was specific for EAA responses because it occurred for glutamate and kainate but not for $\mathrm{ACh}$. In contrast, iontophoretic norepinephrine (NE) selectively attenuated spontaneous activity but not responses evoked by either glutamate or $\mathrm{ACh}$. The responsiveness of LC neurons to EAAs as quantified by a response-contrast measure (evoked excitation/basal activity) was markedly reduced by $5-H T$, but was increased by NE. For ACh, such responsiveness of LC cells was not changed by $5-\mathrm{HT}$, but was increased by NE. The effects of 5-HT were prevented and reversed by iontophoretically applied antagonists of 5-HT receptors, methysergide and methiothepin. Thus, 5-HT appears to selectively interact with EAA responses of LC neurons, acting as a filter to attenuate LC activity linked to its major EAA inputs while allowing other channels afferent to the LC (e.g., those utilizing $A C h$ ) to be expressed.
\end{abstract}

The nucleus locus coeruleus $(\mathrm{LC})$ receives a dense innervation of serotonergic fibers and terminals in both the rodent (Pickel et al., 1977; Steinbusch, 1984; Pieribone et al., 1989) and the primate (Pieribone et al., 1988). Substantial 5-HT input to the rat LC is also indicated by high levels of 5-HT (5-hydroxytryptamine; Pujol et al., 1978; McRae-Degueurce and Milon, 1983), of 5-HT uptake in tissue samples including LC (Léger and Descarries, 1978; McRae-Degueurce et al., 1981), and by substantial 5-HT binding in the LC (Weismann-Nanopoulos et al., 1985). This prominent innervation indicates that 5-HT may play an important role in regulating discharge of noradrenergic LC neu-

\footnotetext{
Received July 17, 1990; revised Oct. 5, 1990; accepted Oct. 19, 1990.

We thank Carl Chiang for assistance in data analysis, Elisabeth Van Bockstaele for photographic assistance, Drs. John Lehmann and Michel Buda for helpful discussions, and Dr. Ramin Shiekhattar for helpful comments on the manuscript. This work was supported by INSERM, CNRS, U.S. Public Health Service Grants NS 24698 and DA 06214, the Simne et Cino Del Duca Foundation, and the Philippe Foundation.

Correspondence should be addressed to Gary Aston-Jones, Ph.D., Division of Behavioral Neurobiology, Department of Mental Health Sciences, MS 403, Hahnemann University Medical School, Broad and Vine, Philadelphia, PA 19102. Copyright (C) 1991 Society for Neuroscience 0270-6474/91/110760-10\$03.00/0
}

rons, a role that could have significant functional implications for brain 5-HT systems. Given the role proposed for the noradrenergic LC system in vigilance and attention (Aston-Jones and Bloom, 1981; Aston-Jones, 1985, 1988; Aston-Jones et al., 1990b, in press), stress (Svensson, 1987; Valentino, 1988; Valentino and Wehby, 1988), and various clinical disorders (reviewed in Aston-Jones et al., 1984), 5-HT inputs to the LC may extend the functional influence of central 5-HT systems beyond that directly conveyed by the ubiquitous 5-HT fiber projections. In particular, interactions between serotonergic and noradrenergic systems have been implicated in control of the sleep-waking cycle (Jouvet, 1969; Hobson et al., 1986; McCarley and Massaquoi, 1986), depression (Koslow et al., 1983; Meltzer and Lowy, 1987; Seiver, 1987), pain (Segal, 1979; Mokha et al., 1985; Jones and Gebhart, 1987, 1988), and anxiety (Redmond and Huang, 1979; Charney and Redmond, 1983; Charney et al., 1983, 1987; Uhde et al., 1984; Kahn et al., 1988; Eison, 1989). The 5-HT innervation of the LC is a possible substrate for such proposed interactions.

Despite the functional implications of this anatomical connection between monoamine systems in brain, the effect of 5-HT on activity of LC neurons has been little investigated. Intravenous $5-\mathrm{HT}_{2}$ agonists or hallucinogens potentiate the sensory responsiveness of LC neurons in anesthetized animals (Aghajanian, 1980; Rasmussen and Aghajanian, 1986; Rasmussen et al., 1986; Chiang et al., 1990); this effect appears to be mediated at an extracoerulear 5-HT synapse. In the only study of the effects of directly applied 5-HT on LC neurons in vivo, Segal (1979) reported that this agent inhibited basal LC discharge and decreased responsiveness of $L C$ neurons to painful stimuli.

In the present study, we have reexamined 5-HT's action on LC discharge in vivo using more recently developed microiontophoretic and micropressure techniques for local drug application. In particular, recent studies reveal that activation of LC neurons by noxious stimuli is mediated by an excitatory amino acid (EAA) input (Ennis and Aston-Jones, 1988; Rasmussen and Aghajanian, 1989a,b). This result, in view of Segal's observation (Segal, 1979) that 5-H'T decreased responses of LC neurons to noxious stimuli, led us to systematically investigate possible interactions between 5- $\mathrm{HT}$ and glutamate (Glu) in the LC. Our results reveal that 5-HT has no pronounced or consistent effect on basal LC discharge, but that this agent potently and selectively attenuates responses of LC neurons to EAAs.

Some of these results have been published in short communications (Chouvet et al., 1988a,b). 
Table 1. Discharge rates of LC neurons during local applications of 5-H', Glu, and ACh

\begin{tabular}{lllll} 
Agent tested & $\begin{array}{l}\text { Basal discharge } \\
\text { rate }\end{array}$ & $\begin{array}{l}\text { Rate with } \\
\text { Glu or ACh alone }\end{array}$ & $\begin{array}{l}\text { Rate with } \\
\text { 5-HT alone }\end{array}$ & $\begin{array}{c}\text { Rate with 5-HT } \\
\text { + Glu or ACh }\end{array}$ \\
\hline Glu $(n=116)$ & $2.4 \pm 0.1$ & $5.7 \pm 0.2^{* *}$ & $2.0 \pm 0.1^{* *}$ & $3.3 \pm 0.2^{* * \dagger}$ \\
ACh $(n=11)$ & $2.6 \pm 0.4$ & $5.3 \pm 0.7^{* *}$ & $2.6 \pm 0.5$ & $4.9 \pm 0.7$ \\
\hline
\end{tabular}

All observations in each row were made on the same population of cells, $n=116$ or $n=11$, as indicated. All rates are given in spikes per sec (mean \pm SEM). ${ }^{* *}, p<0.01$ when compared to basal discharge rate; $\dagger, p<0.01$ when compared to rate with agent alone; 2 -tailed paired Student's $t$ test.

\section{Materials and Methods}

Surgery. Subjects for this study were 30 male, albino Sprague-Dawley rats (300-350 gm; OFA strain, IFFA-Credo, France). Animals were initially anesthetized with halothane $(2 \%)$ via a face mask while the femoral vein was catheterized ( 11 animals) and a tracheal cannula was implanted. Animals were then anesthetized with a halothane-air mixture $(0.8-1.2 \%)$ administered with spontaneous respiration through the tracheal cannula. Body temperature was maintained at $37^{\circ} \mathrm{C}$ with a feedback-controlled heating pad. The animals were mounted in a stereotaxic device, an incision was made to expose the dorsal skull surface, and the snout was lowered to place bregma $2 \mathrm{~mm}$ below lambda. A craniotomy (3-5-mm diameter) was drilled over the coordinates for the LC (3.8-4 mm caudal to the lambda suture crossing, and $1.2 \mathrm{~mm}$ lateral to the midline), and the dura and pia were carefully removed.

Microelectrodes. Eight-barrel composite micropipettes were used for recording extracellular impulse activity from single neurons and simultaneously applying pharmacologic agents by microiontophoresis or by micropressure. Electrodes were manufactured in 2 stages. First, a 7-barrel pipette array was made by heating and pulling a bundle of 7 capillary tubes whilc twisting them $120^{\circ}$, producing a single fine tip containing all 7 barrels. This tip was broken back to a total diameter of $12-20 \mu \mathrm{m}$, and the shank was heated and bent at a $20^{\circ}$ angle $10 \mathrm{~mm}$ from the tip. The tip was then positioned immediately adjacent to that of a single-barrel recording micropipette (2-4- $\mu \mathrm{m}$ tip diameter) using precision micromanipulators so that the recording pipette tip extended $12-20 \mu \mathrm{m}$ beyond the 7 barrel tip. The pipettes were permanently joined in this position using light-sensitive dental cement (Silux, 3M). All pipettes were cemented together on the day of the experiment.

Drug application. Prior to recording, each pipette of the 7-barrel array was filled with one of the following agents: 5 - $\mathrm{HT} \mathrm{HCl}(0.2 \mathrm{M}$; $\mathrm{pH}, 4$; Sigma), norepinephrine bitartrate (NE; $0.2-0.5 \mathrm{M} ; \mathrm{pH}, 4$; Sigma), monosodium glutamate (Glu; $0.1-1 \mathrm{M} ; \mathrm{pH}, 8 ;$ Sigma), acetylcholine chloride (ACh; $0.2 \mathrm{~m} ; \mathrm{pH}, 4$; Sigma), clonidine $\mathrm{HCl}(0.1 \mathrm{~m}$ in $0.2 \mathrm{M} \mathrm{NaCl} ; \mathrm{pH}$, 4; Boeringher Mannhcim), kynurenic acid (Kyn; $0.2 \mathrm{M}$; pH, 8; Sigma), kainate $(0.2 \mathrm{M} ; \mathrm{pH}, 8$; Sigma), saline $(\mathrm{NaCl}, 154 \mathrm{~mm})$, magnesium chloride $(\mathrm{Mg} ; 0.1$ or $1.0 \mathrm{M})$, methiothepin maleate (MTT; $10-30 \mathrm{~mm} ; \mathrm{pH}$, 4; Hoffman La Roche, Switzerland), metergoline (MTG; $20 \mathrm{~mm}$; $\mathrm{HH}$, 3-4; Farmitalia, Italy), or methysergide maleate (MTS; $20 \mathrm{~mm}$; $\mathrm{pH}, 3-$ 4; Sandoz, Switzerland). All solutions except MTT and MTG were dissolved in deionized water, and if necessary, $\mathrm{pH}$ was adjusted with $\mathrm{HCl}$ or $\mathrm{NaOH}(0.1$ or $1.0 \mathrm{M})$. MTT and MTG were dissolved in deionized water with the aid of a few drops of $1 \mathrm{M}$ tartaric acid. Glu, Kyn, kainate, $\mathrm{ACh}$, and $\mathrm{Mg}$ were aliquoted and stored at $-20^{\circ} \mathrm{C}$ until used; all other solutions were made fresh daily.

The center and 1 outer barrel of each pipette contained saline for automatic current balancing and for control ejections of saline with balanced current. A 5-channel current pump with programmable timer (Bionic Instruments) was used for drug delivery by iontophoresis with automatic current balancing and precisely controlled currents and times of application. Drugs were ejected with positive currents and retained with negative currents except for Glu, Kyn, and kainate, which were ejected with negative, and retained with positive currents. Iontophoretic currents of up to $200 \mathrm{nA}$ were used for drug ejections, and retaining currents of 5-20 nA were used to retard leakage of drugs from pipettes between periods of ejection. Drugs were applied either as regularly repeating pulses (typically 10-20-sec pulse durations, with 20-60-sec interpulse intervals) or continuously. Pipette barrels were "warmed up" before data acquisition for each drug and each cell by ejecting drug with the desired test current and temporal pattern until a stable response appeared (typically requiring $2-5 \mathrm{~min}$ ). In some experiments, 1 barrel of the 7-barrel array was also connected to a pneumatic ejection device
(Medical Systems PPM-2), allowing ejection of drug from the same pipette barrel by means of pressure or current.

Recording techniques. Filtered $(300 \mathrm{~Hz}$ to $10 \mathrm{kHz}$ band-pass signal; AC) and unfiltered (DC) recording pipette signals were amplified (Grass P16 preamplifier), discriminated, displayed, and stored on analog tape using conventional electronics. Spikes were used for data only if they were superimposing impulses from a single neuron with amplitudes at least 3 times the noise level. Discriminator output pulses and analog signals proportional to the magnitudes of iontophoretic currents were fed to a chart recorder (Gould 2600) after integration over $1-5 \mathrm{sec}$, as well as to a microcomputer (via Cambridge Electronic Design 1401 interface and software) for display, storage, and later analysis off line.

Extracellular recordings from LC neurons were identified on line by their characteristic discharge properties, including (1) a prominent initially positive waveform in unfiltered signals, (2) a broad, notched waveform (typically with initial segment and late positive spike components, especially in filtered signals), (3) slow tonic basal discharge (typically 14 spikes/sec), and (4) a brisk, phasic excitatory response to painful stimuli such as contralateral paw pinch, followed by a prolonged period (about $1 \mathrm{sec}$ ) of postactivation inhibition (Cedarbaum and Aghajanian, 1976; $\Lambda$ ghajanian et al., 1977; Aston-Jones et al., 1980, 1982, 1984).

Experimental protocol. When a single neuron was isolated, spontaneous discharge was recorded for at least $3 \mathrm{~min}$ before drug tests. For several cells, 5-HT was pulsed (typically $20-60$-sec pulses) to examine possible effects on spontaneous discharge; in other neurons, the effects of 5-HT on basal discharge were only examined between pulses of Glu or ACh. Glu was regularly pulsed (typically $10-\mathrm{sec}$ pulses), and current was adjusted to produce a response of $2-3$ times baseline activity. When stable responding was established, 5-HT was continuously applied (over 2-3 min) simultaneously with the pulsed Glu. Glu pulses continued for at least 2 min after cessation of 5-HT to determine recovery from 5-HT effects. Similarly, for the same or for a different cell, ACh alone was regularly pulsed (typically $20-30$-sec pulses) until a stable response was observed, and then 5-HT was continuously co-applied for 2-3 min, followed by $\Lambda \mathrm{Ch}$ pulses alone again for $2 \mathrm{~min}$ after cessation of the 5-HT application to ascertain recovery. In several cases, ACh was tested before Glu on the same cells; results were similar for this order of testing. For some cells, NE was substituted for 5-HT in the above paradigm (in some cases, the same cell was tested with both 5-HT and NE with pulses of Glu and $\mathrm{ACh}$ ). Also, for some cells, Glu was given continuously, and 5-HT or NE was co-applied in pulses onto the neuron recorded.

Data analysis. Negative current $(10 \mu \mathrm{A}$ for $10 \mathrm{~min}$, pulsed at $0.1 \mathrm{~Hz})$ was used to deposit pontamine sky blue dye from the tip of the recording micropipette in most brains; subsequent histologic analyses demonstrated that such recording sites were located in the compact nucleus of noradrenergic LC neurons. These results, and those of our previous experiments (Aston-Jones et al., 1984), led us to conclude that all neurons recorded with the characteristic discharge properties described above were obtained from LC neurons. Because the nucleus LC in the rat is composed almost entirely of noradrenergic neurons (Foote et al., 1983; Aston-Jones et al., 1984), we further conclude that these results were obtained from noradrenergic neurons.

Cells yielding stable, high-quality recordings throughout testing procedures were subjected to quantitative analysis; cells that were lost during testing, that did not recover from a drug treatment, or that yielded unstable responses to Glu or ACh were used only for qualitative observations. All spike counts were taken from computer records of integrated (5-sec bin width) impulse activity. Basal discharge rates of individual cells were determined for at least 3 separate 10 -sec epochs preceding pulses of Glu or ACh. The influence of locally applied agents on LC discharge was quantified using the mean firing rate during at least 3 applications. 

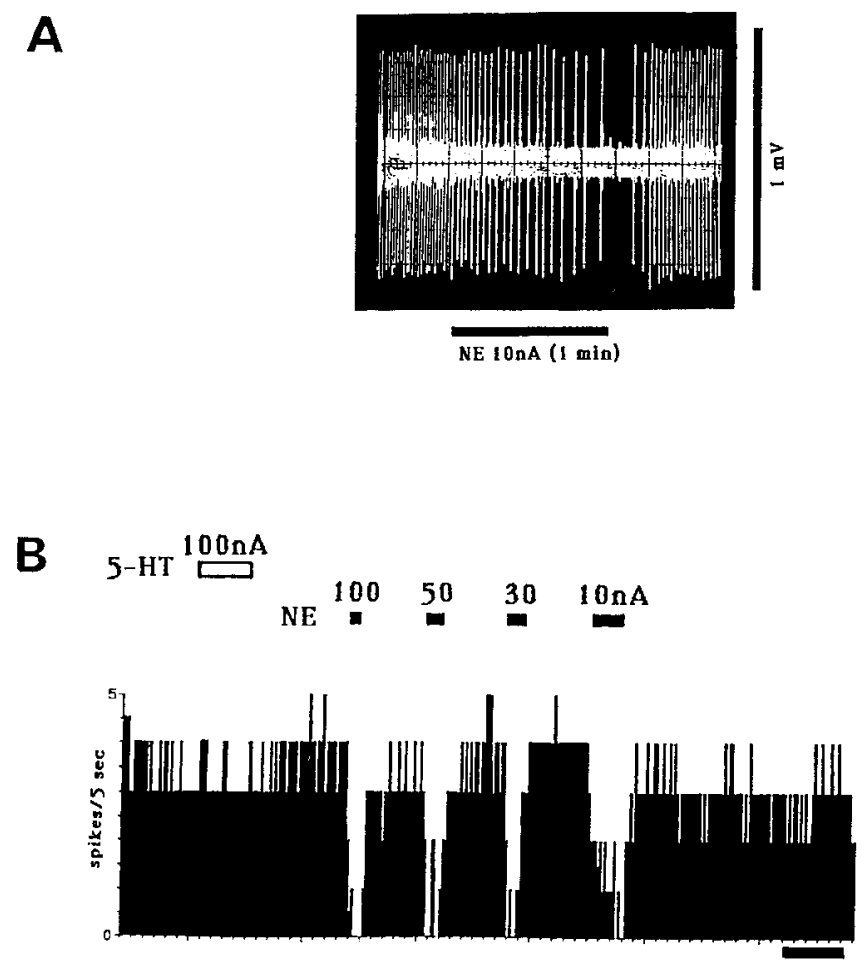

Figure 1. Effects of 5-HT and NE on spontaneous activity of an LC neuron. $A$, Oscilloscope photograph of response of an LC neuron to iontophoretic application of $\mathrm{NE}(10 \mathrm{nA}$; bar below): same recording as for the last pulse of NE on the chart record in B. Calibration: horizontal, I min; vertical, $1 \mathrm{mV}$. B, Iontophoretic 5-HT (100 nA; open bar) had little effect on spontancous discharge of this same LC neuron, while NE at much lower currents (as indicated by solid bars) inhibited spontaneous activity. Calibration, $2 \mathrm{~min}$.

A criterion of at least $15 \%$ change from baseline activity was used during drug application for individual cells to estimate the number of neurons responsive to a particular transmitter agent. This criterion represents a change of approximately 2 standard deviations from baseline activity characteristic of LC cells in anesthetized animals (determined from within-cell variability measurements).

Comparisons of absolute firing rates of the same cells under different conditions (Table 1) were performed using the 2-tailed paired Student's $t$ test. Other comparisons were performed with the nonparametric Wilcoxon signed ranks test for paired observations and a significance criterion of $p<0.05$

To examine the effects of NE and 5-HT on the responsiveness of LC neurons to Glu and $\mathrm{ACh}$, the response of $\mathrm{LC}$ neurons to Glu or $\mathrm{ACh}$ during continuous application of 5-HT or NE was expressed as a percentage of the response magnitude $\left(R_{\mathrm{mag}}\right)$ elicited by Glu or ACh applied to the same cell alone. The response magnitude for Glu or $\mathrm{ACh}$ alone was determined for each cell during a series of at least 3 pulses and was defined as the mean number of spikes during the last $10 \mathrm{sec}$ of each of 3 iontophoretic pulses minus the mean number of spikes during the 10 sec preceding that pulse.

The Glu or ACh response contrast $\left(R_{\text {con }}\right)$ was also determined for each cell. The response contrast for $\mathrm{Glu}$ or $\mathrm{ACh}$ alone was defined as the corrcsponding ratio of response magnitude : basal rate. If one assumes that basal activity corresponds to cellular "noise," and evoked activity, to "signal," this measure would be the signal-to-noise ratio for evoked $\mathrm{LC}$ responses. The response contrast for Glu or $\mathrm{ACh}$ in the presence of continuous 5-HT or NE was expressed as a fraction of the response contrast for Glu or ACh alone observed for the same cell.

Changes in response magnitude or response contrast elicited by $5-\mathrm{H}^{\prime} \mathrm{I}$ or NE were statistically analyzed by comparing normalized values in the presence of these agents (\% response magnitude or relative response contrast) to 100 or to 1 (corresponding to baseline response magnitude or response contrast, respectively).

\section{Results}

Basal discharge. Two hundred thirty-two neurons with discharge properties characteristic of LC neurons (described in Materials and Methods) were recorded in 30 rats. Recordings with composite microelectrodes were consistently of high quality, typically yielding stable impulse waveforms of $0.5 \mathrm{mV}$ or greater (approximately 10 times baseline noise level; see Figs. 1, 4).

The sample of $232 \mathrm{LC}$ neurons exhibited basal discharge rates of $0.4-7.5 \mathrm{spikes} / \mathrm{sec}$, with a median rate of $2.0 \mathrm{spikes} / \mathrm{sec}$ and a mode around $1.8 \mathrm{spikes} / \mathrm{sec}$. The mean $( \pm \mathrm{SEM})$ basal discharge rate for this population of $L C$ neurons was $2.3 \pm 0.1$ spikes/sec, similar to rates reported in previous studies using halothane anesthesia (Aston-Jones et al., 1984). The basal discharge of some cells, however, was probably elevated by Glu leaking from the iontophoretic pipette despite continuous retaining current (described below).

Response to 5-HT or other agents given alone. Iontophoretic (50-200 nA; $n=136$ cells) or micropressure-applied 5-HT (10$20 \mathrm{psi} ; n=15$ cells) yielded inconsistent effects on basal LC discharge (Fig. $1 B$ ). Using a response criterion of at least a $15 \%$ change in activity, iontophoretic 5-HT decreased activity of many cells (51/109 neurons) but increased activity ( $9 / 109$ neurons) or had no effect on many other LC neurons (49/109 cases). Overall, basal activity was reduced $14 \pm 2 \%$ by iontophoretic 5 -HT $(n=109$ cells; $p<0.01$; Table 1$)$ and $10 \pm 3 \%$ by micropressure-applied 5-HT $(n=7)$.

In contrast, other putative transmitter agents in the same pipettes and applied to the same LC neurons yielded pronounced, consistent results. Rapid and potent inhibitory responses were elicited by iontophoresis of NE (23/25 cells; Fig. 1) or of GABA (13/13 cells; data not shown). Iontophoretic clonidine also inhibited each of 3 LC neurons tested, though with a longer latency of action than for NE (30 sec or more compared to about $5 \mathrm{sec}$; data not shown). In addition, 201 of 211 LC neurons were reliably and potently activated by Glu (Figs. 2, 3; Table 1); activation by Glu typically required currents of 10-50 nA for $5 \mathrm{sec}$. For several cells, increasing the retaining current for Glu from +5 to $+20 \mathrm{nA}$ substantially decreased basal activity, indicating that Glu leakage with normal retaining currents (5-10 nA) may have been sufficient to increase impulse activity. LC cells were also strongly activated by the EAA agonist kainate ( $6 / 6$ cells tested; data not shown); sensitivity to this agent appeared to be higher than that to Glu. Finally, LC neurons were reliably activated by $\mathrm{ACh}$ (22/25 cells; Figs. 3, 4; Table 1), though higher currents and longer pulses (typically 50-150 $\mathrm{nA}$ for $15 \mathrm{scc}$ ) were required compared to Glu or kainate.

Serotonergic attenuation of response to Glu. As shown in Figure 2, 5-HT consistently decreased responses of $\mathrm{LC}$ neurons to iontophoretic Glu. Typically, 5-HT (50-200 nA) reduced excitation evoked by Glu (the $R_{\text {mag }}$ for Glu in the presence of 5-HT $=43 \pm 4 \%$ of the $R_{\text {mag }}$ for Glu alone; $n=109 ; p<0.01$ ) while having little or no effect on the level of basal activity of the same neuron (Table 1). Such attenuation of Glu-evoked activation by $5-\mathrm{HT}$ was, in fact, independent of its effects on basal activity, such that Glu responses were reduced by 5-HT even for cells exhibiting increased basal activity after administration of this agent (Fig. 2C), as well as for those in which 5-HT elicited a decrease (Fig. $2 A$ ) or no change in resting discharge (Fig. $2 B, E, F)$.

We noted that, though 5-HT consistently attenuated responses of $\mathrm{LC}$ neurons to Glu, in most cases, such responses 
A
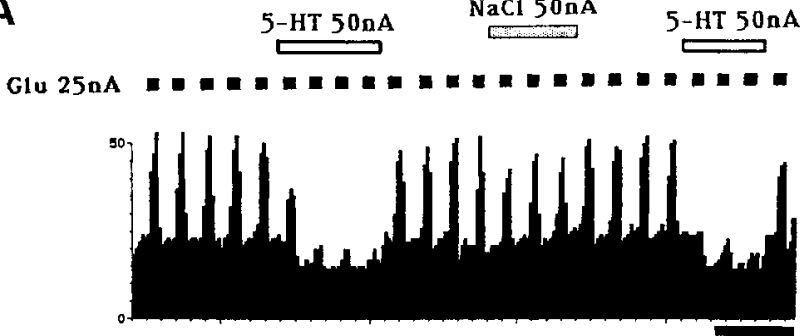

B

Glu $6 \mathrm{nA} \quad \operatorname{lonA}$

KYN 70nA

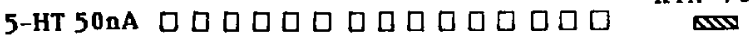

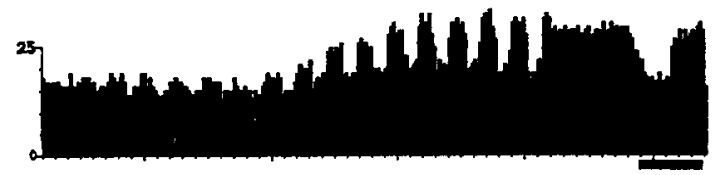

C

$$
\text { 5-HT 100nA }
$$

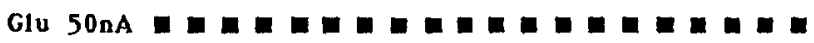

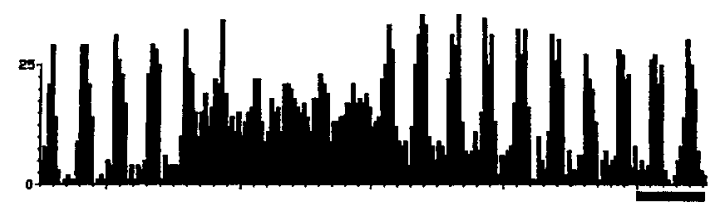

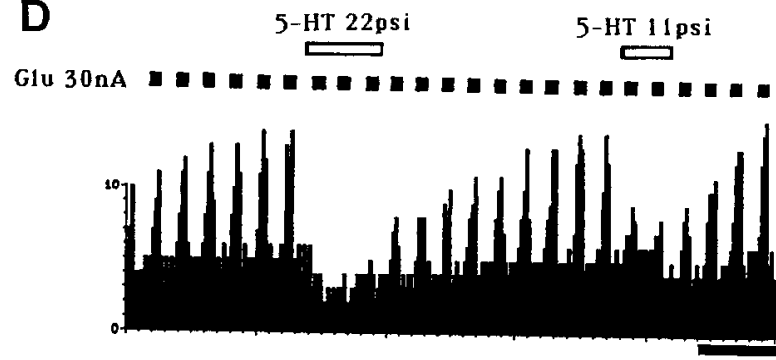

$\mathbf{E}$
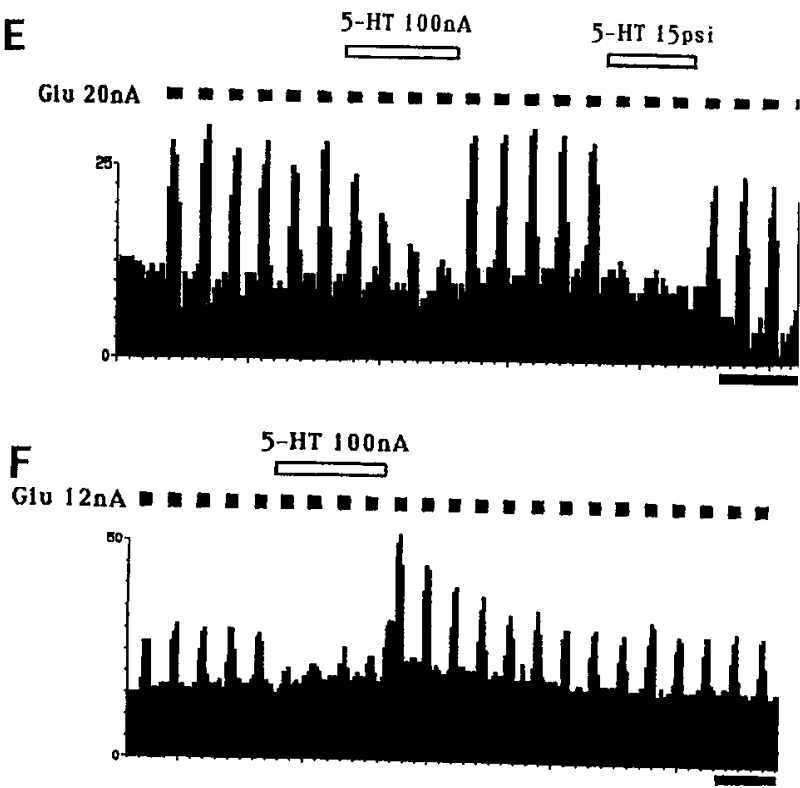

Figure 2. Computer-generated integrated activity-time histograms, revealing interactions of 5-HT and Glu on LC discharge. $A$, Pulses of Glu (applied at solid bars) activate a typical LC neuron. Co-iontophoresis of 5-HT (applied at open bars), but not of saline (applied at stippled bar), attenuates Glu response but has little effect on basal discharge. B, Pulses of 5-HT (applied at open bars) elicit little effect on basal activity (at lefi) but substantially reduce tonically enhanced activity elicited by continuously applied Glu (applied at solid bars). Note that the EAA antagonist Kyn (applied at hatched bar) also decreases tonic Glu-evoked discharge, mimicking effect of 5-HT. C, Iontophoretic 5-HT (applied at open bar) attenuates Glu responses (applied at solid bars) even in cases where 5-HT increases basal discharge, as here. D, 5-HT applied by pressure (at open bars) attenuates responses to iontophoretic Glu (applied at solid bars), mimicking effect of iontophoretic 5-HT. Note the slow recovery after 5-HT application. E, 5-HT applied by pressure or by iontophoresis (at open bars) on the same cell and with the same barrel has the same effect of decreasing responsiveness to Glu (applied at solid bars). $F$. Increased responsiveness to Glu (applied at solid bars) after cessation of an iontophoretic pulse of 5-HT (applied at open bars). Different neurons are displayed in $A-F$. Ordinates, number of spikes per 5 sec; abcissas, time. Calibration, 2 $\min$.

were not entirely blocked, even when 5-HT currents were increased. In addition, 8 cells (7\%) displayed a prominent increase in response to Glu immediately after cessation of 5-HT appli(adtion (Fig. 2F). This effect was not studied in detail.

Two series of experiments were performed to confirm that the decrease of Glu responsiveness effected by iontophoretic 5-HT was not an artifact of the iontophoretic technique. (1) For most cells, the same current used to eject 5-HT was passed through the side barrel containing saline; automatic current balancing through the center barrel was routinely used with both 5 -HT and saline iontophoresis. As depicted in Figure $2 A$, saline iontophoresis never mimicked the effect of 5-HT. Moreover, similar effects of 5-HT were also observed when automatic current compensation was not used, indicating that current artifacts were negligible with these pipettes and currents. (2) 5-HT was applied by micropressure through the same (iontophoretic) pipette barrel, and results were compared to those with iontophoretic application. As can be seen in Figure 2, $D$ and $E$, results with micropressure-applied 5-HT closely resembled those found for iontophoretic 5-HT, with 14 of 15 cells tested exhibiting decreased responsiveness to Glu in the presence of 5-HT (the $R_{\text {mag }}$ for Glu in the presence of 5-HT applied by pressure $=31$ $\pm 6 \%$ of the $R_{\text {mas }}$ for Glu alone; $n=7 ; p<0.05$ ). There was no difference between the decreases in Glu responses induced by 5 -HT co-applied by iontophoresis versus by pressure (MannWhitney $U$ test for nonpaired samples, $p>0.26$ ). In addition, the same cells $(n=3)$ tested with both iontophoretic and pressure application of 5-HT from the same barrel exhibited similar decreases of Glu responses (Fig. 2E). Finally, the specificity of Glu effects was demonstrated by the ability of the EAA antagonist Kyn to block Glu-induced activation of the LC ( $4 / 4$ cells tested with Kyn iontophoresis, $6 / 7$ cells tested with pressureapplied Kyn; Fig. 2B).

We analyzed the decrease in the absolute value of the Glu $R_{\text {mag }}$ induced by 5 -HT to determine if it varied with the $R_{\text {mag }}$ for Glu before 5-HT application. There was a strong positive correlation between these 2 factors $(r=0.78 ; p<0.01)$, indicating that 5-HT attenuated large Glu responses more than small 
A 5-HT IOOnA

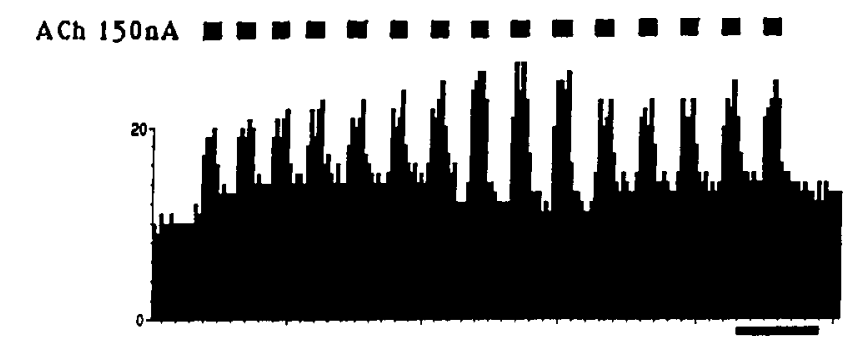

B
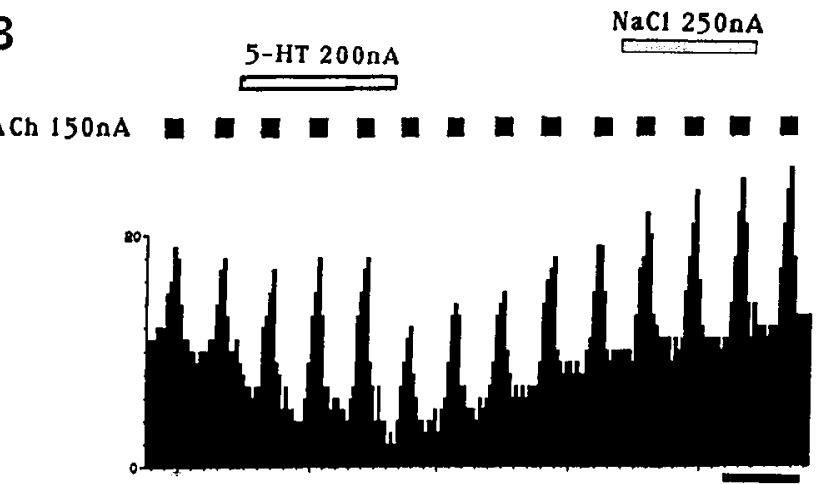

Figure 3. Effects of 5-HT on responses of LC neurons to ACh. $A$, Iontophoretic 5-HT (applied at open bar) does not attenuate, and even slightly augments, responses to iontophoretic ACh (applied at solid bars). $B, 5-\mathrm{HT}$ iontophoresed at high current (applied at open bar) fails to attenuate responses to $\mathrm{ACh}$ (iontophoresed at solid bars) even in cases where basal activity is reduced, as here. Note that application of saline (at stippled bar) has no effect on either basal or ACh-evoked activity. Different neurons are shown in $A$ and $B$. Calibrations are as in Figure 2 .

responses. Thus, there was a similar level of activity in the presence of Glu plus 5-HT independent of the initial responsiveness to Glu alone.

In addition, 5-HT applied by micropressure attenuated kainate-induced excitation in 3 of 5 cells tested (data not shown). Micropressure application of Kyn also blocked kainate excitations in the 1 cell tested.

Ineffectiveness of 5-HT on responses to ACh. The specificity of 5-HT's action on Glu responsivity was tested by examining its effects on responsiveness of $\mathrm{LC}$ neurons to ACh. In contrast to its attenuation of Glu responses, 5-HT did not decrease responses of LC neurons to ACh (Figs. 3, 4A; Table 1). ACh responses were not reduced for 5 of 6 cells with 5-HT applied by iontophoresis, nor for 4 of 5 cells with micropressure application of 5 -HT (the $R_{\text {mag }}$ for ACh in the presence of 5-HT $=99$ $\pm 11 \%$ of the $R_{\operatorname{mag}}$ for ACh alone; $n=11 ; p>0.60$ ). Responses to ACh remained intact even in cases where 5-HT reduced LC basal discharge rate (Fig. 3B).

Noradrenergic attenuation of basal, but not evoked, LC activity. $\Lambda$ s a further test of 5-HT's specificity in attenuating Glu responses, its effects were compared to those of iontophoretic NE. As shown in Figure 4, NE and 5-HT had strikingly different influences on LC activity. Whereas 5-HT reliably attenuated responses to Glu without prominently altering basal discharge or responses to $\mathrm{ACh}$, amounts of NE sufficient to strongly decrease basal activity did not decrease responses to co-applied Glu or ACh.

The effects of 5-HT and NE on evoked LC activity are com-
A
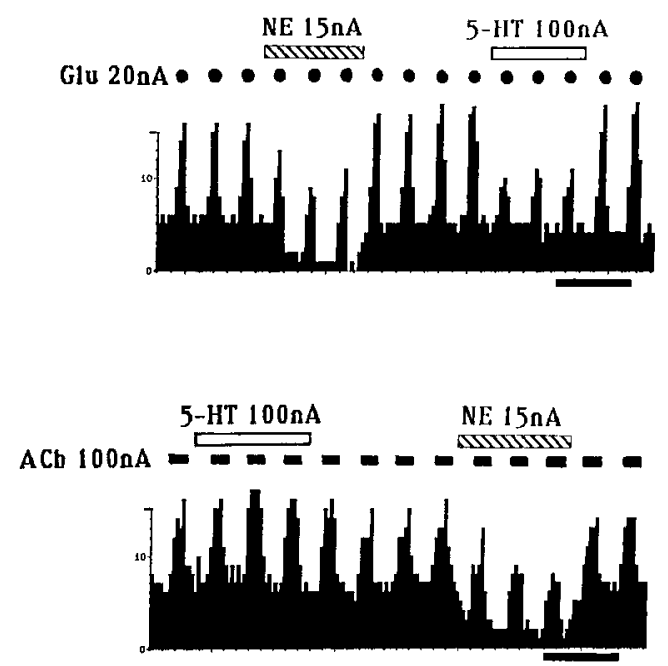

B
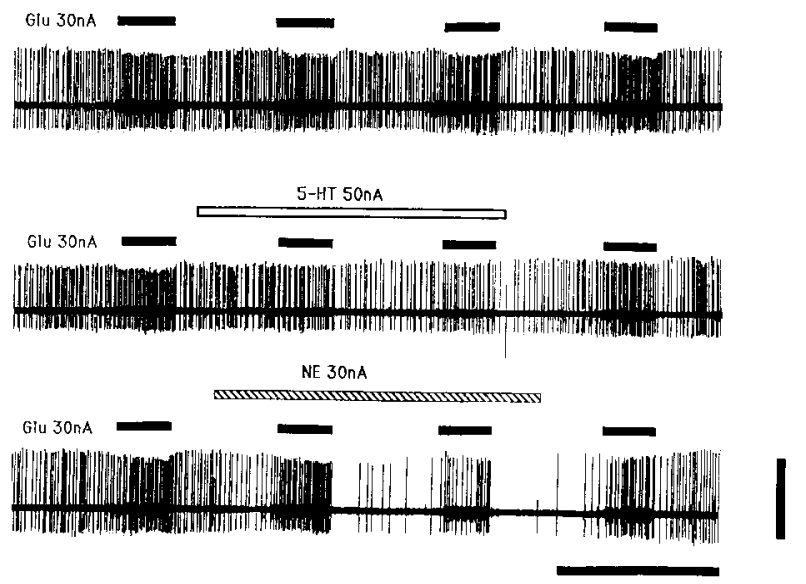

Figure 4. Comparison of NE and 5-HT effects on responses to Glu and $\mathrm{ACh}$ for the same LC neuron. $A$, NE applied with a long pulse of low current (at hatched bars) inhibits basal activity but leaves responses evoked by Glu (applied at solid circles, upper trace) or ACh (applied at solid bars, lower trace) intact. In contrast, 5-HT applied in long pulses (at open bars) does not affect basal discharge rate, but attenuates responses to Glu (upper trace). Note that, though responses to Glu are attenuated by $5-\mathrm{HT}$, responses of the same neuron to ACh remain intact during application of 5-HT (lower trace). Both traces were recorded from the same LC neuron. Calibrations are as in Figure 2. B, Filtered micropipette recording, showing LC extracellular impulses during iontophoretic application of 5-HT, NE, and Glu. For this typical LC neuron, responses to Glu (applied at solid bars) are attenuated by iontophoresis of 5-HT (applied at open bar, middle trace) while basal discharge rate is little affected. In contrast, iontophoretic NE (applied at hatched bar, lower trace) attenuates basal discharge but is less effective on Glu responses. All traces were recorded from the same LC neuron (different from neuron in $A$ ). Calibration, $1 \mathrm{mV}$ (ordinates), $1 \mathrm{~min}$ (abcissas).

pared in Figure 5 with normalized values of $R_{\text {mag }}$ and $R_{\text {con }}$ for both Glu and ACh (see Materials and Methods for computation of $R_{\text {mag }}$ and $R_{\text {con }}$ ). As illustrated in Figure 5, 5-HT markedly decreased the $R_{\text {mas }}$ for Glu overall $(p<0.01)$ and, because it had little effect on baseline activity, also substantially decreased the $R_{\text {con }}$ observed for Glu in the LC $(p<0.01)$. However, the $R_{\text {mag }}$ and $R_{\text {con }}$ for ACh were not affected by 5 -HT $(p>0.60$ for each). A very different pattern of effects was found for NE. NE did not significantly influence the $R_{\text {mag }}$ for either Glu- or AChevoked activity in the LC $(p>0.12$ and 0.20 , respeclively; Fig. $5 A$ ), but by virtue of its potent suppression of basal discharge, 


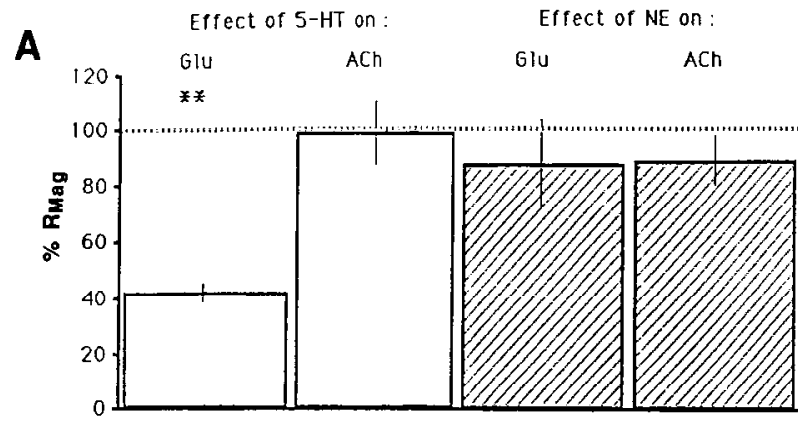

Effect of 5-HT on:

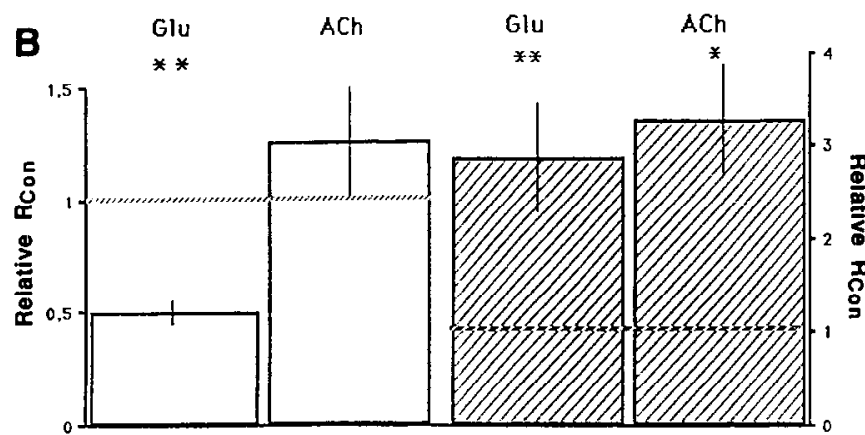

Figure 5. A, Effect of 5-HT (open bars) or NE (hatched bars) on average \pm SEM $R_{\text {Mag }}$ elicited by Glu or ACh, as indicated. The $R_{\text {Mag }}$ under 5-HT or NE was calculated for each cell as percentage of the $R_{\mathrm{Mag}}$ for Glu or ACh alone on the same cell (see Materials and Methods for calculation of $R_{\mathrm{Mag}}$ ). Changes in $R_{\mathrm{Mag}}$ elicited by $5-\mathrm{HT}$ or NE were statistically analyzed by comparing such values in the presence of these agents $\left(\% R_{\text {mag }}\right.$ ) to 100 (baseline $R_{\text {(ag }}$ ). Note that $5-\mathrm{HT}$ (iontophoresis or pressure) significantly attenuated responses to Glu $\left(n=116 ;{ }^{* *}, p<\right.$ $0.01)$, but not to $\mathrm{ACh}(n-11 ; p>0.60)$, and that NE did not significantly alter the average $R_{\text {Mag }}$ for either Glu $(n=10 ; p>0.10)$ or ACh $(n=4$; $p>0.20$ ). $B$. Effect of 5-HT (open bars) or NE (hatched bars) on average $\pm \mathrm{SEM} R_{\text {Con }}$ for Glu and $\mathrm{ACh}$, as indicated ( $R_{\text {con }}=R_{\text {mag }}$ /basal activity): same cell population as in $A$. The $R_{\text {Con }}$ under 5-HT or NE was calculated for each cell as a fraction of the $R_{\text {Con }}$ for Glu or ACh alone on the same cell. Changes in $R_{\text {Con }}$ elicited by 5-HT or NE were statistically analyzed by comparing such values in the presence of these agents (relative $R_{\text {Con }}$ ) to 1 (haseline $R_{\text {Con }}$ ). Note that 5-HT substantially decreases the $R_{\text {Con }}$ for Glu (**, $p<0.01)$ but not for ACh $(p>0.60)$, while NE, because of its attenuation of basal discharge, markedly increases the $R_{\text {Con }}$ for both Glu (**,p<0.01) and ACh $(*, p<0.05)$. Note also the different scales for 5-HT effects (indicated at left) versus NE effects (indicated at right).

NE markedly increased the $R_{\text {con }}$ in the LC for both Glu and ACh $(p<0.01$ and $p<0.05$, respectively; Fig. $5 B)$.

Attenuation of 5-HT effects by antagonists. To test whether the observed effects were mediated by 5-HT receptors, the 5-HT receptor antagonists MTS, MTT, and MTG were co-iontophoresed with 5-IIT during iontophoretically pulsed Glu. As shown in Figure 6, application of MTS or MTT attenuated the 5-HTelicited reduction of Glu responses in the LC. (11/15 and 4/5 neurons, respectively). More specifically, MTS prevented effects of 5-HT on 3 of 4 neurons (Fig. 6A) and reversed 5-HT actions on 8 of 11 cells tested. Similarly, MTT prevented 5-HT effects on the 1 cell tested and reversed 5-HT for 3 of 4 cells (Fig. $6 B$ ). Quantitative analyses revealed that both MTS and MTT significantly reduced the effect of 5-HT on Glu responsiveness ( $p$
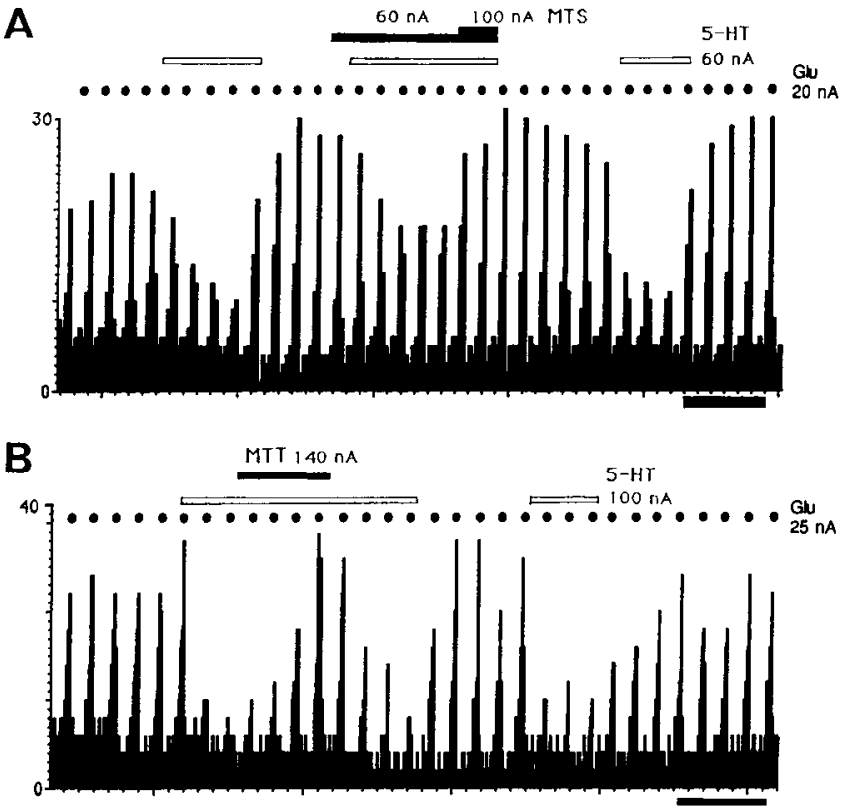

Figure 6. Antagonists of 5-HT receptors attenuate effects of 5-HT on LC neurons. $A$, Attenuation of response to Glu (applied at solid circles) by 5-HT (applied at open bars) is prevented by prior and co-iontophoresis of MTS (applied at solid bars). B, Attenuation of response to Glu (applied at solid circles) by 5-HT (applied at open bars) is reversed by co-iontophoresis of MTT (applied at solid bar). Different neurons are shown in $A$ and $B$. Calibrations are as in Figure 2.

$<0.05$ for each; $n=6$ and 4 , respectively; Fig. 7). As also seen in Figure 7, these agents tended to enhance Glu responsiveness in the presence of 5-HT above that seen without 5-HT (however, this effect was not significant; $p>0.10$ for both). In addition, application of either MTS or MTT without 5-HT in some cases augmented Glu-evoked activity as well (data not shown). MTG increased noise in recordings and yielded apparent depolarization with loss of the recorded spike either under Glu ( $5 / 5$ cells) or when applied alone ( $3 / 5$ cells); results with this agent were therefore excluded.

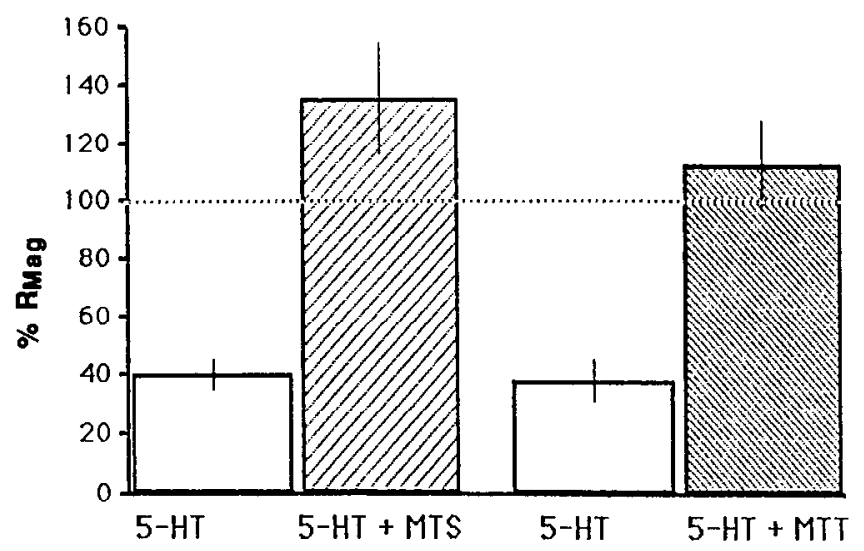

Figure 7. Effects of MTS or MTT on attenuation of Glu-cvoked activity in the LC by $5-\mathrm{HT}$. Results are expressed as percentage (mean \pm $\mathrm{SEM})$ of $R_{\text {mag }}\left(\% R_{\mathrm{Mag}}\right.$ ) elicited for Glu alone in the same neurons (see Fig. 5). Separate populations of cells were tested for MTS and for MTT. Both MTS $(n=6)$ and MTT $(n=4)$ antagonized the effect of 5-HT on responses to Glu: The $R_{\text {Mag }}$ for Glu observed with 5-HT plus the antagonist is significantly greater than the Glu $R_{\mathrm{Mag}}$ observed with $5-\mathrm{HT}$ alone $\left(^{*}, p<0.05\right)$. See Materials and Methods for calculation of $R_{\text {Mag }}$. 


\section{Discussion}

Selectivity and specificity of 5-HT actions in the LC. The present results demonstrate selective and specific effects of 5-HT on noradrenergic LC neurons. 5-HT was found to decrease Gluevoked activation of LC cells by an average of about $50 \%$. This effect of 5-HT was selective in several ways: (1) 5-HT had only a small effect overall (14\% decrease) on basal discharge of LC cells, with many cells remaining unaffected. Even the modest inhibition of tonic LC activity by 5-HT may reflect attenuation of Glu responses evoked either by Glu leakage from adjacent iontophoretic barrels (discussed above) or by a tonic (jlu input. The previous finding that Kyn application produced a modest inhibition of LC activity (Ennis and Aston-Jones, 1988) is consistent with this latter possibility. (2) Unlike the marked decrease in Glu responses, 5-HT had no effect on excitatory responses of $\mathrm{LC}$ neurons to $\mathrm{ACh}$ and no effect on the $R_{\text {con }}$ for $\mathrm{ACh}$. (3) Unlike 5-HT, NE applied to LC neurons with low iontophoretic currents reliably decreased basal discharge but did not substantially alter excitatory responses to either Glu or ACh. Due to its preferential attenuation of basal activity, NE yielded a substantial increase in Glu and ACh $R_{\text {con }}$ of LC neurons.

The effects of 5-HT in LC were found to be specific to 5-HT mechanisms: (1) Similar effects were seen for 5-HT applied by iontophoresis with or without compensating current, or when applied by micropressure. These results demonstrate that the effects observed for 5-HT were independent of the method of delivery and are not an artifact of iontophoretic currents. (2) The ability of 5-HT to attenuate responses of LC neurons to Glu was prevented and reversed by co-application of the 5-HT receptor antagonists MTT or MTS. Interestingly, MTT or MTS sometimes increased responsiveness to Glu when administered alone. While these agents may increase Glu responsiveness by mechanisms other than 5-HT antagonism, they fully reverse 5-HT effects and exhibit a tendency to increase Glu responsiveness above baseline even in the presence of 5-HT. These findings indicate that these agents may effectively block all 5-HT effects in the LC and may augment Glu responsiveness beyond baseline by antagonizing a tonic 5-HT input to the LC. It is also possible that they antagonize effects of 5-HT that may leak from the iontophoretic micropipette. It should be noted that MTT and MTS are not absolutely selective for 5-HT receptors, with MTT, in particular, exhibiting binding to histamine, $\alpha$-adrenergic, and dopamine receptors as well (Leysen et al., 1981). Antagonism of 5-HT actions by these agents, therefore, suggests but does not definitively demonstrate that effects were exerted at 5-HT receptors in our experiments. However, other of our studies in progress (Charléty et al., 1990; Aston-Jones et al., 1990 a) reveal that 5 -HT's effects in the LC are mimicked by 5-HT la $_{\text {a }}$ agonists, including 8-hydroxy-2-[ $N, N$-dipropylamino]tetralin (8-OHDPAT), RU24969, and buspirone, further supporting our conclusion that 5-HT attenuates Glu responses by acting at a 5-HT receptor (possibly of the 5- $\mathrm{HT}_{1 \mathrm{a}}$ subtype).

Previous studies of 5-HT in the LC. Segal (1979) reported that 5-HT iontophoretically applied to LC neurons of anesthetized rats substantially decreased basal discharge rate. Although the effects of 5-HT on LC activity were not quantified in that study, it appears that more profound inhibition of spontaneous activity was found there than here. The reason for this difference is uncertain, but contributing factors may include differences in microiontophoretic electrode techniques, anesthetics, or experimental protocols.

That previous study also found that 5-HT attenuated the response of LC neurons for noxious stimuli. We have reported that responses of LC neurons to noxious stimuli (such as from sciatic nerve activation or tail compression) are mediated by an EAA pathway to the LC from the rostral ventrolateral medulla (Aston-Jones and Ennis, 1988; Ennis and Aston-Joncs, 1988; Chiang and Aston-Jones, 1989; Aston-Jones et al., 1990b). In view of this, our present results imply that 5-HT may block LC responses to painful stimuli, as reported by Segal (1979) by attenuating responses of $\mathrm{LC}$ neurons to EAAs.

Intracellular studies by Bobker and Williams (1989) in vitro have revealed effects of 5-HT on LC neurons very similar to those reported here. Using electrical field stimulation of the periLC area in slices to elicit synaptic potentials in LC neurons, these investigators found that 5-HT attenuated both excitatory and inhibitory synaptic potentials without substantially affecting resting membrane properties. Because these synaptic potentials are mediated by Glu and GABA, respectively (Cherubini et al., 1988 ), these findings indicate that 5 -HT in vitro attenuates responses of LC neurons to synaptically released Glu, similar to results obtained here for exogenously applied Glu in vivo. This slice study, however, found that the 5-HT 1 agonist 5-carboxamidotryptamine was ineffective on responses to exogenously applied Glu, even though this agent potently attenuated Glumediated excitatory synaptic potentials. The reason for this discrepancy with our results is not apparent, but may have to do with their use of the in vitro slice preparation and bath application of pharmacologic agents.

Interactions between 5-HT and EAAs in other brain areas. Studies in other brain areas have reported interactions between 5-HT and EAAs similar to those found here in the LC. Krnjevic and Phillis (1963) reported that 5-HT attenuated responses of cortical neurons to iontophoretic Glu. Aghajanian and Bunney (1975) found that application of 5-HT to presumed dopaminergic neurons of the substantia nigra attenuated responses to Glu while having no pronounced effect on spontaneous discharge; possible interactions of 5-HT with other neurotransmitters were not tested. Strahlendorf and colleagues (Strahlendorf and Hubbard, 1983; Lee et al., 1986) found that iontophoretically applied 5-HT had variable effects on spontaneous discharge of cerebellar Purkinje cells, but that 5-HT consistently attenuated activation of cerebellar Purkinje cells by Glu, independent of effects on spontaneous activity. This action of 5-HT was antagonized by co-iontophoresis of MTS, indicating a spccific cffcct at 5-HT receptors. Crepel and associates (Gardette et al., 1987) reported that 5-HT had differential effects on neurons in the deep cerebellar nuclei in vitro, increasing spontaneous discharge of most cells, but attenuating their responses to iontophoretically applied EAAs. Persistence of those effects in low-calcium/high-magnesium solutions indicated a postsynaptic site of action.

Although several studies have found that 5-HT attenuates responses to EAAs, other effects are reported for some CNS areas. Reynolds and colleagues (Reynolds et al., 1988) and $\mathrm{Ne}$ dergaard et al. (1987) found that 5-HT increased the response of neocortical neurons to EAAs. In addition, facial (McCall and Aghajanian, 1979) and spinal motoneurons (White and Neuman, 1980, 1983) have been reported to exhibit increased responsiveness to Glu as a result of 5-H'l exposure. 'These 5-HT 
cffects on motoncurons do not appcar to be spccific to EAAs, but rather, may result from overall increased neuronal excitability subsequent to a 5-HT-induced decrease in resting K-conductance (VanderMaelen and Aghajanian, 1980, 1982). Thus, the interaction between 5-HT and EAAs differs for different brain areas.

Mechanism of 5-HT actions in the LC. The selective attenuation of Glu or kainate responses by 5-HT resembles the action expected of an EAA antagonist. In fact, there is a marked similarly between the actions of 5-HT and the EAA antagonist Kyn in the $\mathrm{LC}$, as seen in Figure $2 B$. However, the attenuation of Glu-evoked LC activity by $5-\mathrm{HT}$ was prevented and antagonized by the 5-HT antagonists MTS and MTT, suggesting that 5 -HT receptors specifically mediate this response. Additional studies with more selective 5-HT agents support this conclusion and indicate that a $5-\mathrm{HT}_{1 \mathrm{a}}$ receptor is primarily involved (Charléty et al., 1990; Aston-Jones et al., 1990). Therefore, 5-HT is probably not acting as an EAA antagonist in the LC. In addition, analysis revealed a strong positive correlation between the degree of attenuation of the Glu $R_{\text {mag }}$ by $5-\mathrm{HT}$ and the Glu $R_{\text {mas }}$ before 5-HT application. This result indicates that 5-HT may not have acted at the same receptor site as Glu, because such a correlation would not be expected for competitive antagonism.

The precise site of action of 5-HT in attenuating Glu-evoked activity in the LC is uncertain. Microiontophoretic or micropressure application of 5-HT assures that effects are mediated within the LC, but does not discriminate between possible preor postsynaptic sites of action. Because 5-HT has no pronounced effect on resting $\mathrm{LC}$ activity but primarily acts to attenuate activity evoked by Glu, to operate presynaptically, 5-HT would presumably block neurotransmitter release evoked presynaptically by iontophoretic Glu. In preliminary experiments to test whether activation of LC neurons by Glu was mediated by a presynaptic action, we continuously iontophoresed $\mathrm{Mg}$ (to decrease release of neurotransmitter from presynaptic terminals) and pulsed Glu. $\mathrm{Mg}$ had variable effects in the $\mathrm{LC}$, frequently decreasing spontaneous and Glu-evoked activity to a similar extent, perhaps reflecting decreased LC excitability. However, there was no preferential decrease of Glu responses compared to baseline activity. Because Glu remained relatively effective in the presence of $\mathrm{Mg}$, these results suggest that iontophoretic Glu acts, at least in part, directly on LC cells, and that 5-HT therefore acts to some extent postsynaptically on LC neurons as well. However, because the effectiveness of iontophoretic or micropressure application of $\mathrm{Mg}$ in attenuating transmitter release in vivo is uncertain, these conclusions must remain tentative.

Results of in vitro studies where 5-HT agonists attenuated synaptic potentials mediated by Glu, but not depolarizations in response to exogenous Glu application, led Bobker and Williams (1989) to conclude that 5-HT acts presynaptically to block Glu release from nerve terminals innervating the $\mathrm{LC}$. However, if in our study 5-HT blocks transmitter release evoked by Glu, it is unclear why such Glu-evoked transmitter release was not observed in their study, or why, if such a release occurred, it was not blocked by 5 -HT. There are many possible explanations for the differences between our results, including unknown but perhaps important differences between LC properties in vitro and in vivo. Further experiments are necessary to determine the precise site(s) of action of 5-HT in the LC.

Functional implications. The present results indicate that 5-HT acts primarily to modulate the response of $\mathrm{LC}$ ncurons to other inputs rather than independently increasing or decreasing their discharge. Furthermore, the selective interaction of 5-HT with responses of $\mathrm{LC}$ neurons to Glu, while having little effect on their tonic, spontaneous discharge or on their responsiveness to another neurotransmitter (ACh), indicates that 5-HT may selectively filter or gate certain afferents to the LC.

Although several investigators have proposed that the dorsal raphe provides the bulk of 5-HT input to the LC (Palkovits et al, 1977; Segal, 1979; Léger et al., 1980; McRae-Degueurce and Milon, 1983; Imai et al., 1986); recent studies employing retrograde and anterograde transport (Aston-Jones et al., 1986, 1990; Pieribone and Aston-Jones, 1988; Pieribone et al., 1988) as well as lesions (Pieribone et al., 1989) have found that dorsal raphe 5-HT neurons do not substantially innervate the LC. Recent experiments employing retrograde transport of lectincoupled gold particles discretely injected into the LC combined with immunohistochemistry indicate that local 5-HT neurons in the pericoerulear central gray substantially innervate the LC (Pieribone and Aston-Jones, 1990). Thus, local circuit neurons may provide the endogenous 5-HT input to selectively modulate LC responsiveness as described herein.

Two functionally distinct events have been shown to activate the LC by an EAA input to the LC. Ennis and Aston-Jones have demonstrated that the characteristic activation of $L C$ neurons by electrical footpad stimulation of the sciatic nerve is due to an EAA input, with intracerebroventricular (Ennis and AstonJones, 1988) as well as with local (Aston-Jones and Ennis, 1988) EAA antagonists acting to block this response. These results have recently been confirmed by others (Rasmussen and Aghajanian, 1989a,b). The second EAA influence on LC neurons occurs during morphine withdrawal, as evidenced by the blockade of characteristic withdrawal-induced hyperactivity of LC neurons by intracerebroventricular (Rasmussen and Aghajanian, 1989b) or intracoerulear (Akaoka et al., 1990) application of the EAA antagonist Kyn. Studies are underway to examine whether 5-HT attenuates phasic sensory responses of LC neurons or their tonic activation during opiate withdrawal. Such possible modulation of I C sensory responses by 5 -HT would be consistent with the previous results of Segal (1979).

Inasmuch as LC and NE systems have been implicated in anxiety, fear, and startle (Davis et al., 1979; Redmond and Huang, 1979; Adams and Geyer, 1981; Charney and Redmond, 1983; Charney et al., 1983), the recent finding that some 5-HTacting anxiolytics such as buspirone or gepirone block fearpotentiated startle (Kehnc ct al., 1988; Mansbach and Geyer, 1988) may reflect, in part, an interaction of these compounds with 5 -HT receptors in the LC. Indeed, in preliminary studies iontophoretic buspirone attenuates responses of LC neurons to Glu, similar to results reported here for 5-HT (Charléty et al., 1990).

It is significant for the present findings that EAAs are the most prominent input to the $\mathrm{LC}$ from its major afferent in the ventrolateral medulla (Aston-Jones et al., 1986, 1990; Ennis and Aston-Jones, 1987, 1988; Aston-Jones and Ennis, 1988). This result, in view of the potent interaction observed here between 5-HT and the response of LC neurons to EAAs, indicates that 5-HT is in a position to potently and selectively modulate the response of the LC system to its functionally preeminent afferents. 


\section{References}

Adams LM, Geyer MA (1981) Effects of 6-hydroxydopamine lesions of locus coeruleus on startle in rats. Psychopharmacology (Berlin) 73 : 394-398.

Aghajanian GK (1980) Mescaline and LSD facilitate the activation of locus cocruleus neurons by peripheral stimuli. Brain Res 186:492498.

Aghajanian GK, Bunney BS (1975) Dopaminergic and non-dopaminergic neurons of the substantia nigra: differential responses to putative transmitters. In: Neuropsychopharmacology: proceedings of the congress of the Collegium Internationale Neuropsychopharmacologicum (Bousier JR, Hippius H, Rohot P, eds), pp 444-452. Amsterdam: Excerpta Medica.

Aghajanian GK, Cedarbaum JM, Wang RY (1977) Evidence for norepinephrine-mediated collateral inhibition of locus coeruleus neurons. Brain Res 136:570-577.

Akaoka H, Drolet G, Chiang C, Aston-Jones G (1990) Local, naloxone-precipitated withdrawal in the ventrolateral medulla activates locus coeruleus neurons via an excitatory amino acid pathway. Soc Neurosci Abstr 16:1027.

Aston-Jones G (1985) Behavioral functions of locus coeruleus derived from cellular attributes. Physiol Psychol 13:118-126.

Aston-Jones G (1988) Cellular attributes of locus coeruleus: implications for attentional processes. In: Progress in Catecholamine Research, Part B: Clinical Aspects (Sandler M, Dahlstrom A, Belmaker $R$, eds), pp 133-142. New York: Liss.

Aston-Jones G, Bloom FE (1981) Norepinephrine-containing locus coeruleus neurons in behaving rats exhibit pronounced responses to non-noxious environmental stimuli. J Neurosci 1:887-900.

Aston-Jones G, Ennis M (1988) Sensory-evoked activation of locus coeruleus may be mediated by a glutamate pathway from the rostral ventrolateral medulla. In: Frontiers in excitatory amino acid research (Cavalheiro A, Lehmann J, Turski L, eds), pp 471-478. New York: Liss.

Aston-Jones G, Segal M, Bloom F (1980) Brain aminergic axons exhibit marked variability in conduction velocity. Brain Res 195:215222

Aston-Jones G, Foote SL, Bloom FE (1982) Low doses of ethanol disrupt sensory responses of brain noradrenergic neurones. Nature 296:857-860.

Aston-Jones G, Foote SL, Bloom FE (1984) Anatomy and physiology of locus coeruleus neurons: functional implications. In: Frontiers of clinical neuroscience, Vol 2, norepinephrine (Ziegler M, Lake CR, eds), pp 92-116. Baltimore: Williams and Wilkins.

Aston-Jones G, Ennis M, Pieribone VA, Nickell WT, Shipley MT (1986) The brain nucleus locus coeruleus: restricted afferent control of a broad efferent network. Science 234:734-737.

Aston-Jones G, Charlety P, Akaoka H, Shcikhattar R, Chouvet G (1990a) Serotonin acts at 5- $\mathrm{HT}_{1 \mathrm{~A}}$ receptors to selectively attenuate glutamateevoked responses of locus coeruleus neurons. Soc Neurosci Abstr 16: 799

Aston-Jones G, Shipley MT, Ennis M, Williams JT, Pieribone VA (1990b) Restricted afferent control of locus coeruleus neurons revealed by anatomic, physiologic and pharmacologic studies. In: The pharmacology of noradrenaline in the central nervous system (Marsden CA, Heal DJ, eds), pp 187-247. Oxford: Oxford UP.

Aston-Jones $\mathrm{G}$, Chiang $\mathrm{C}$, Alexinsky $\mathrm{T}$ (in press) Discharge of noradrenergic locus coeruleus neurons in behaving rats and monkeys suggests a role in vigilance. Prog Brain Res.

Bobker DH, Williams JT (1989) Serotonin agonists inhibit synaptic potentials in the rat locus ceruleus in vitro via 5-hydroxytryptamine $l_{A}$ and 5-hydroxytryptamine ${ }_{B}$ rcceptors. J Pharmacol Exp Ther 250: 37-43.

Cedarbaum JM, Aghajanian GK (1976) Noradrenergic neurons of the locus coeruleus: inhibition by epinephrine and activation by the $\alpha$-antagonist piperoxane. Brain Res 112:413-419.

Charléty PJ, Akaoka H. Aston-Jones G, Chouvet G (1990) In vivo pharmacological characterization of the serotonin receptors involved in the interaction with excitatory amino acids in the nucleus locus coeruleus of the rat. Eur J Neurosci [Suppl] 3:30.

Charney DS, Redmond DE (1983) Neurobiological mechanisms in human anxiety. Evidence supporting central noradrenergic hyperactivity. Ncuropharmacology 22:1531-1536.

Charney DS, Heninger GR, Redmond DE (1983) Yohimbine induced anxiety and increased noradrenergic function in humans: effects of diazepam and clonidine. Life Sci 33:19-29.

Charney DS, Woods SW, Goodman WK, Heninger GR (1987) Serotonin function in anxiety. II. Fffects of the serotonin agonist MCPP in panic disorder patients and healthy subjects. Psychopharmacology (Berlin) 92:14-24.

Cherubini E, North RA, Williams JT (1988) Synaptic potentials in rat locus coeruleus neurones. J Physiol (Lond) 406:431-442.

Chiang C, Aston-Jones G (1989) Microinjection of lidocaine, GABA or synaptic decouplers into the ventrolateral medulla blocks sciaticevoked activation of locus coeruleus. Soc Neurosci Abstr 15:1012.

Chiang C, Shiekhatter R, Aston-Jones G (1990) Enhancement of sensory-evoked responses in rat locus coeruleus by the 5-HT2 agonist 1-(2,5-dimethoxy-4-iodophenyl)-2-aminopropane (DOI). Soc Neurosci Abstr 16:799.

Chouvet G, Aston-Jones G, Akaoka H, Malekaki E (1988a) Serotonin selectively decreases glutamate-evoked excitation of locus coeruleus in vivo. Soc Neurosci Abstr 14:216.

Chouvet G, Akaoka H, Aston-Jones G (1988b) Serotonin selectively decreases glutamate-induced excitation of locus coeruleus neurons. $\mathrm{C}$ R Acad Sci (Paris) 306:339-344.

Davis M, Redmond DJ, Baraban JM (1979) Noradrenergic agonists and antagonists: effects on conditioned fear as measured by the potentiated startle paradigm. Psychopharmacology (Berlin) 65:111-118.

Eison MS (1989) The new generation of serotonergic anxiolytics: possible clinical roles. Psychopathology 22:13-20.

Ennis M, Aston-Jones G (1987) Two physiologically distinct populations of neurons in the ventrolateral medulla innervate the locus coeruleus. Brain Res 425:275-282.

Ennis M, Aston-Jones G (1988) Activation of locus coeruleus from nucleus paragigantocellularis: a new excitatory amino acid pathway in brain. J Neurosci 8:3644-3657

Foote SL, Bloom FE, Aston-Jones G (1983) Nucleus locus ceruelus: new evidence of anatomical and physiological specificity. Physiol Rev 63:844-914.

Gardette R, Krupa M, Crepel F (1987) Differential effects of serotonin on the spontaneous discharge and on the excitatory amino acid-induced responses of deep cerebellar nuclei neurons in ral cerebellar slices. Neuroscience 23:491-500.

Hobson JA, Lydic R, Baghdoyan HA (1986) Evolving concepts of sleep cycle generation: from brain centers to neuronal populations. Behav Brain Sci 9:371-448.

Imai H, Steindler DA, Kitai ST (1986) The organization of divergent axonal projections from the midbrain raphe nuclei in the rat. J Comp Neurol 243:363-380.

Jones SI, Gebhart GF (1987) Spinal pathways mediating tonic, coeruleospinal, and raphe-spinal descending inhibition in the rat. J Neurophysiol 58:138-159.

Jones SL, Gebhart GF (1988) Inhibition of spina! nociceptive transmission from the midbrain, pons and medulla in the rat: activation of descending inhibition by morphine, glutamate and electrical stimulation. Brain Res 460:281-296.

Jouvet M (1969) Biogenic amines and the states of sleep. Science 163: $32-41$.

Kahn RS, van Praag HM, Wetzler S, Asnis GM, Barr G (1988) Serotonin and anxiety revisited. Biol Psychiatry 23:189-208.

Kehne JH, Cassella JV, Davis M (1988) Anxiolytic effects of buspirone and gepirone in the fear-potentiated startle paradigm. Psychopharmacology $94: 8-13$.

Koslow SH, Maas JW, Bowden CL, Davis JM, Hanin J, Javaid J (1983) CSF and urinary biogenic amines and metabolites in depression and mania. Arch Gen Psychiatry 40:999-1010.

Krnjevic K, Phillis JW (1963) Actions of certain amines on cerebral cortical neurones. Br J Pharmacol 20:417-490.

Lee M, Strahlendorf JC, Strahlendorf HK (1986) Modulatory action of serotonin on glutamate-induced excitation of cerebellar Purkinje cells. Brain Res 361:107-113.

Léger L, Descarries L (1978) Serotonin nerve terminals in the locus coeruleus of the adult rat: a radioautographic study. Brain Res 145: $1-13$.

Léger L, McRae-Degueurce A, Pujol JF (1980) Origine de l'innervation sérotoninergique du locus coeruleus chez le rat. C R Acad Sci (Paris) 290:807-810

Leysen JE, Awouters F, Kennis L, I aduron PM, Vandenberk J, Janssen PAJ (1981) Receptor binding profile of $R 41468$, a novel antagonist 
at 5-HT2 receptors. Life Sci 28:1015-1022.

Mansbach RS, Geyer MA (1988) Blockade of potentiated startle responding in rats by 5-hydroxytryptamine-1A ligands. Eur J Pharmacol 156:375-383.

McCall RB, Aghajanian GK (1979) Serotonergic facilitation of facial motoneuron excitation. Brain Res 169:11-27.

McCarley RW, Massaquoi SG (1986) A limit cycle mathematical model of the REM sleep oscillator system. Am J Physiol 251:R1011R1029.

McRae-Degueurce A, Milon H (1983) Serotonin and dopaminergic afferents to the rat locus coeruleus: biochemical study after lesioning of the ventral mesencephalic tegmental-A10 region and the raphe dorsalis. Brain Res 263:344-347.

McRae-Degueurce A, Léger L, Wiklund L, Pujol JF (1981) Functional recuperation of the serotonergic innervation in the rat locus coeruleus. J Physiol (Paris) 77:389-392.

Meltzer HY, Lowy MT (1987) The serotonin hypothesis of depression. In: Psychopharmacology: the third generation of progress (Meltzer HY, ed), pp 513-525.

Mokha SS, McMillan JA, Iggo A (1985) Descending control of spinal nociceptive transmission. Actions produced on spinal multireceptive neurones from the nuclei locus coeruleus (LC) and raphe magnus (NRM). Exp Brain Res 58:213-226.

Nedergaard S, Engberg I, Flatman JA (1987) The modulation of excitatory amino acid responses by serotonin in the cat neocortex in vitro. Cell Mol Neurobiol 7:367-379.

Palkovits M, Saavedra JM, Jacobowitz DM, Kizer JS, Záborszky L, Brownstein MJ (1977) Serotonergic innervation of the forebrain: effect of lesions on serotonin and tryptophan hydroxylase levels. Brain Res 130:121-134.

Pickel VM, Joh TH, Reis DJ (1977) A serotonergic innervation of noradrenergic neurons in nucleus locus coeruleus: demonstration by immunocytochemical localization of transmitter specific enzymes tyrosine hydroxylase. Brain Res 131:197-214.

Pieribone VA, Aston-Jones G (1988) The iontophoretic application of fluoro-gold for the study of afferents to deep brain nuclei. Brain Res 475:259-271.

Pieribone VA, Aston-Jones G (1990) Serotonergic innervation of the rat locus coeruleus. Eur J Pharmacol [Suppl] 3:231.

Pieribone VA, Aston-Jones G, Bohn MC (1988) Adrenergic and nonadrenergic neurons of the $\mathrm{Cl}$ and $\mathrm{C} 3$ areas project to locus coeruleus: a fluorescent double labeling study. Neurosci Lett 85:297-303.

Pieribone VA, Van Bockstaele EJ, Shipley MT, Aston-Jones G (1989) Serotonergic innervation of rat locus coeruleus derives from nonraphe brain areas. Soc Neurosci Abstr 15:420.

Pujol JF, Keane P, McRae A, Lewis BD, Renaud B (1978) Biochemical evidence for serotonergic control of the locus coeruleus. In: Interactions between putative neurotransmitters in the brain (Garattini $\mathrm{S}$, Pujol JF, Samanin R, eds), pp 401-410. New York: Raven.

Rasmussen K, Aghajanian GK (1986) Effect of hallucinogens on spontaneous and sensory-evoked locus coeruleus unit activity in the rat: reversal by selective 5-HT2 antagonists. Brain Res 385:395-400.

Rasmussen K, Aghajanian GK (1989a) Failure to block responses of locus coeruleus neurons to somatosensory stimuli by destruction of two major afferent nuclei. Synapse 4:162-164.
Rasmussen K and Aghajanian GK (1989b) Withdrawal-induced activation of locus coeruleus neurons in opiate-dependent rats: attenuation by lesions of the nucleus paragigantocellularis. Brain Res 505: 346-350.

Rasmussen K, Glennon RA, Aghajanian GK (1986) Phenethylamine hallucinogens in the locus coeruleus: potency of action correlates with rank order of 5-HT2 binding affinity. Eur J Pharmacol 132:79-82.

Redmond DJ, Huang YH (1979) Current concepts. II. New evidence for a locus coeruleus-norepinephrine connection with anxiety. Life Sci 25:2149-2162.

Reynolds JN, Baskys A, Carlen PL (1988) The effects of serotonin on $N$-methyl-D-aspartate and synaptically evoked depolarizations in rat neocortical neurons. Brain Res 456:286-292.

Segal M (1979) Serotonergic innervation of the locus coeruleus from the dorsal raphe and its action on responses to noxious stimuli. J Physiol (Lond) 286:401-415.

Seiver LJ (1987) Role of noradrenergic mechanisms in the etiology of the affective disorders. In: Psychopharmacology: the third generation of progress (Meltzer HY, ed), pp 493-504.

Steinbusch HWM (1984) Serotonin-immunoreactive neurons and their targets in the CNS. In: Classical transmitters and transmitter reccptors in the CNS, Pt II (Björklund A, Hökfelt T, Kuhar MJ, eds), pp 68118. Amsterdam: Elsevier.

Strahlendorf JC, Hubbard GD (1983) Serotonergic interactions with rat cerebellar Purkinje cells. Brain Res Bull 11:265-269.

Svensson TH (1987) Peripheral, autonomic regulation of locus coeruleus noradrenergic neurons in brain: putative implications for psychiatry and psychopharmacology. Psychopharmacology (Berlin) 92: $1-7$

Uhde TW, Boulenger JP, Post RM, Siever LJ, Vittone BJ, Jimerson DC, Roy BP (1984) Fear and anxiety: relationship to noradrenergic function. Psychopathology 3:8-23.

Valentino RJ (1988) CRH effects on central noradrenergic neurons: relationship to stress. Adv Exp Med Biol 245:47-64.

Valentino RJ, Wehby RG (1988) Corticotropin-rclcasing factor: cvidence for a neurotransmitter role in the locus ceruleus during hemodynamic stress. Neuroendocrinology 48:674-677.

VanderMaelen C, Aghajanian GK (1980) Intracellular studies showing modulation of facial motoneurone excitability by serotonin. Nature 287:346-347.

VanderMaelen CP, Aghajanian GK (1982) Serotonin-induced depolarization of rat facial motoneurons in vivo: comparison with amino acid transmitters. Brain Res 239:139-152.

Weissmann-Nanopoulos D, Mach E, Magre J, Demassey Y, Pujol J-F (1985) Evidence for the localization of 5-HT1A binding sites on serotonin containing neurons in the raphe dorsalis and raphe centralis. Neurochem Int 7:1061-1072.

White SR, Neuman RS (1980) Facilitation on spinal motoneuron excitability by 5 -hydroxytryptaminc and noradrenalinc. Brain Res 188:119-127.

White SR, Neuman RS (1983) Pharmacological antagonism of facilitatory but not inhibitory effects of serotonin and norepinephrine on excitability of spinal motoneurons. Neuropharmacology 22:489-494. 